\title{
Michael Pemberton:
}

'Oral cancer: we must continue to encourage restriction on tobacco and alcohol consumption'

Please send any ideas for feature articles for consideration to:

Ruth Doherty,

Managing Editor,

British Dental Journal

The Macmillan Building,

4-6 Crinan Street,

London,

N1 9XW

Email: r.doherty@nature.com

Ruth Doherty, BDJ Managing Editor, spoke to Michael Pemberton, at the BDA Conference and Exhibition held in Manchester earlier this year.

What inspired you to study dentistry?

I was interested in both people and biology so I always knew I wanted to work in the healthcare profession. Like many children of my generation I required various bits of restorative dental care as a child so I was always in and out of the dentist. When I was deciding what to study I looked at my dentist and he seemed to have a very civilised lifestyle - I marvelled that he was able to disappear off for golf on a Wednesday afternoon. I did also consider becoming a doctor but, at the time, I didn't necessarily want to follow in my elder brother's 'medical student footsteps'. So I decided to become a general dental practitioner. I was attracted not so much to the golf but to a lifestyle of being in control of your working day and the boss of your own team - it's ironic that I'm now in a job that is nothing like a GDP role!

\section{What drew you to studying oral medicine in particular?}

When I finished my dentistry degree, I found that I wasn't sure that being a GDP was right for me. I was always interested in the medical aspects of dentistry so after doing some house jobs in oral surgery and dentistry, I applied to do medicine and worked in general dental practice in the evenings whilst doing my medical degree over the course of

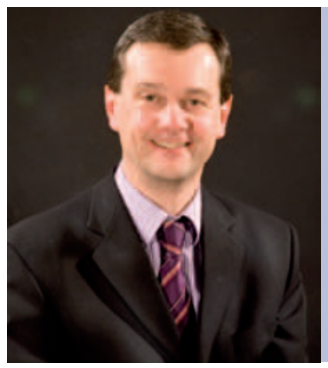

Michael Pemberton is a consultant in oral medicine and the clinical head of the dental division at the University Dental Hospital of Manchester. Mike received both his undergraduate dental and medical degrees at Sheffield. Following a number of junior hospital dental and medical positions and time in general dental practice, he was appointed consultant and honorary lecturer in medicine in dentistry at the University of Manchester in 2000. He is a fellow in dental surgery of the Royal College of Surgeons of Edinburgh and his research interests are focused on the study of oral mucosal disease.

five years. Then, following some junior house jobs in medicine, an opportunity came up as a lecturer in oral medicine at the University of Manchester which for me was the right job in the right place at the right time. I was very fortunate as there were very few training jobs in oral medicine around this time.

What I like about oral medicine is that it is to some extent detective work. There's an intellectual challenge in finding out what is wrong with people and in oral medicine the answer is not always clear because in addition to any physical issues there can be quite a few psychological issues to consider, such as why the patient is seeking help now and possible underlying elements of the complaint. So I enjoy the intellectual side of finding out what is wrong but I also enjoy the therapeutic side of trying to put it right. In most areas of dentistry the problem is a surgical one for which there is a surgical solution but in oral medicine sometimes there is nothing clearly physically wrong with the patient but it is a manifestation of something else that's going on in their life. This is one of the most interesting aspects.

\section{What are you most proud of?}

In my life in general I have to say my wife and family. In my career, it's a combination of things - both treating patients who have had difficulty and have not always been able to access care, and teaching the next generation of dentists coming along. I strongly believe that oral medicine has an important role in teaching as well as in treating.

\section{What is the biggest challenge in teaching the next generation?}

Sometimes it is getting students at undergraduate level to realise that what you are teaching them is relevant even though don't always see the reason why immediately. It's not uncommon for qualified dentists to say to me: 'I'm so glad I learnt that as an undergraduate because when I qualified I realised how important that knowledge was.' 


\section{If you could instigate one change in the NHS to help fight oral cancer what would you do?}

I would continue to encourage restriction on the use of tobacco and excess alcohol consumption in the population both by public health measures and by personal interaction of healthcare professionals with their patients.

I also think the NHS should consider implementing a vaccination scheme for young males against human papillomaviruses (HPV) types 16 and 18. Through the NHS in the UK we currently vaccinate young girls aged 12 against HPV infection to reduce levels of cervical cancer but there is good evidence of HPV also being involved in some forms of penile, anal and oropharyngeal cancer. The case can be made that you should be immunising boys as well to get herd immunity and that would have an influence on the prevalence of these cancers.

What worries you most about the state of public oral health in the UK?

From a dental point of view, we still have sections of our community who have dental disease. Whilst we are making huge advances in many aspects of dentistry, technically and scientifically, not all patients in the UK and globally are yet able to fully benefit from it.

\section{What are your views on the debate regarding the connection between periodontal disease and heart disease?}

There does appear to be an epidemiological association between periodontal disease and heart disease. There have been some reasonable theoretical postulations as to why there might be a causative association. However, it remains to be seen whether it truly is causative. It's certainly an area still in need of further research. Many of the patients who have both heart disease and periodontal disease have lots of confounding factors and it is very difficult to know if it is a true causal association or merely an association through other factors.

Periodontal disease and systemic disease have been looked at in various areas, for example pre-term and low birth weight infants. In epidemiological studies there is a clear association between poor periodontal health and low birth weight and pre-term infants. However, in this case, unlike heart disease, it has been possible to do a measurable intervention by providing periodontal care to a group of early pregnant women and having a control group who didn't get the periodontal care and looking at the outcomes. The evidence from systematic review and meta-analysis is that by giving periodontal care you don't alter the outcomes; so for that it remains an association as opposed to a causative association. It is more difficult to do those studies with heart disease because you don't have that nine month cut-off in the same way. It is also a much more complex disease to look at and this causes difficulty in truly knowing whether there is a causative association to periodontal disease or not.

\section{What is your advice for dental students just about to start at university?}

My advice would be to work hard for the five years and learn as much as you can because the scientific knowledge in dentistry continues to expand year-on-year. The grounding you will get at university will stand you in good stead for whatever you decide to do afterwards.

\section{And for those just about to graduate?}

They are in a period of time where the knowledge within dentistry continues to expand at an exponential rate. We now have materials that were not dreamt of fifty years ago and our knowledge about disease is so much better than it was in the past. They are on threshold of a great opportunity but it will be up to them how they go forwards with it.
What would your 3 desert island research papers be?

Rather than 'desert island papers' these are all papers that have a significant effect on my clinical thinking.

- Lamey P J, Lamb A B. Prospective study of aetiological factors in burning mouth syndrome. BMJ 1988; 296: 1243-1246. I was an oral surgery registrar seeing patients complaining of burning in the mouth and not really knowing how to approach their management. On discovering this paper, I quickly developed a framework for management.

- Ibbotson S H, Speight E L, Macleod R I, Smart E R, Lawrence C M. The relevance and effect of amalgam replacement in subjects with oral lichenoid reactions. Br J Dermatol 1996; 134: 420-423.

I read this paper at the time I began specialist oral medicine training in Manchester under Professor Martin Thornhill. This was a subject, amongst many others, that Martin helped me think more deeply about.

- Haynes A B, Weiser T G, Berry W R et al. A surgical safety checklist to reduce morbidity and mortality in a global population. $N$ Eng J Med 2009; 360: 491-499.

The team who designed and published this important paper was led by Atul Gawande, a surgeon in Boston. He writes really well on medical matters and in my current management role as a clinical head of division, his writing has helped me think critically about patient safely issues.

\section{What luxury would you take to said island?}

If I'm not allowed to take my wife, then a radio to pick up the BBC World Service.

\section{What are the future challenges for dentists in the UK?}

To keep abreast of future scientific developments but the dental profession must still make sure that those patients who are not receiving the care they need, receive it. 